This is close to the published version. For citations:

Ergas, O. (2017). Schooled in our own Minds: Mind-wandering and Mindfulness in the Curriculum. Journal of Curriculum Studies. (ahead of print)

\title{
Schooled in our own Minds: Mind-wandering and Mindfulness in the Curriculum
}

Oren Ergas, Beit Berl College, Israel

\begin{abstract}
Curriculum discourse focuses understandably, on the formal and enacted curriculum; however, studies demonstrate that much of individuals' waking hours are spent in taskunrelated thinking and mind-wandering. No less, this pervasive phenomenon has been shown to affect us in many ways that can be linked to education. This paper examines this nullhidden inner curriculum that is enacted within students' minds when they are not attentive to the formal/enacted curriculum. Drawing on a review of research in cognitive science, the paper develops a theory of 'the mind as a curriculum deliberator' and explains how the mind can be seen as 'schooling itself'. Different states of mind such as mind-wandering, rumination and mindfulness, are discussed in terms of their educational effects and a systematic framework that renders them in curricular terms is suggested. Based on this analysis, the paper aims to mobilize this inner curriculum from opaqueness and absence, to a more explicit presence in curricular discourse, in an attempt to broaden our understanding of how the mind can both enhance and hinder, education.
\end{abstract}

Keywords: absent/null/hidden curriculum, mind, mind-wandering, agency, mindfulness. 
[T] he study of curriculum has been prone to a philosophical oversight known as ontological monovalence by focusing on what is present on curricula to the exclusion of what is absent. (Wilkinson, 2014, p. 419)

\section{Introduction and Method}

Curriculum theorists have understandably been more focused on exploring that which the curriculum includes, rather than on that which it does not include. Nevertheless, some have pointed to the importance of acknowledging the latter domain and its educational effects. Eisner (1979) referred to it as the null curriculum, a term he applied to the knowledge and skills that remain outside of the formal curriculum given their being unacknowledged or ruled out, based on curricular deliberations (Schwab, 1969). Others spoke of the hidden curriculum describing lessons learnt at schools unintentionally (Brown 2009). Wilkinson (2014) recently described the dialectics of absence versus presence in the curriculum, and made a normative claim in regards to the development of curriculum theory and practice: 'The removal of absence is conducive to the development of greater epistemological consistency and ontological wholeness' (p. 423). Building on Bhaskar's (2000) critical realism, he argued that our ability to shed light on absence, can significantly contribute to the task of education. The current paper follows this thread by proposing a curriculum that can be viewed as both null, for it is hardly ever considered in curriculum discourse, and hidden, for as this paper will argue, we are substantially educated by it nevertheless. This curriculum is the inner curriculum, which is comprised of all that students (and teacher) experience when they are not present to the formal/enacted curriculum, but rather attend to content produced by their own minds, to which only they have access. 
The starting point for considering this domain within curricular discourse emerges when we acknowledge a fundamental premise that guides much of public educational practice, which may conflate with the nature of mind. Broadly, educational institutions expect that curricula and pedagogies that are coherently aligned and well-implemented, will yield a 'mind-making process' (Eisner, 1988) that educates students in certain 'goods' that societies envision (Postman, 1995). Setting aside 'who's good' or 'what good', students' minds might not be disposed to heed even the best of our efforts. As James (1983) argued in his Talks to Teachers, '[t]he mind of your own enemy, the pupil, is working away from you as keenly and eagerly as is the mind of the commander on the other side from the scientific general' (p. 10). Indeed, many have observed that much of our day, is spent in mental activity that is not directly related to the task at-hand (Dewey, 1997a; Klinger, 1971), a claim now widely studied in cognitive and neuroscientific research (Christoff, Irving, Fox, Spreng, \& AndrewsHanna, 2016; Smallwood \& Schooler, 2014). There would be an obvious propensity to focus on what a student misses while his mind wanders away from the enacted curriculum, as some have explored (Smallwood, Fishman \& Schooler, 2007). Such propensity will lead us yet again to the enacted/formal curriculum. However, following the call to elucidate absence in curricular theory and practice, there are good reasons to examine these internal workings of the mind in and of themselves. These begin with stark finding from empirical studies that show that our minds spend 30 to 50 percent of their waking hours in spontaneous and nontask related thoughts (Killingstworth \& Gilbert, 2010; Kane et al., 2007). However, it is not merely a matter of quantity, that warrants the orientation proposed in this paper. This substantial part of our mental lives has been found to affect our moods, sense of identity, creativity and cognitive functioning (Baars, 2010; Baird, et al., 2012; Killingsworth \& Gilbert, 2010; Qin \& Nothoff, 2011). These findings call us to inform curricular deliberations by assuming a different angle - the first-person experience of the mind itself. If these internal 
workings of the mind are found to enhance or to hinder our educational intentions, then perhaps we need to study what makes minds wander, and where they wander to (and not only what they wander away from). Indeed some decades ago, Pinar \& Grumet (1976) acknowledged the wandering mind in the classroom (p. 10) and argued that 'we have gone just about as far as we can go in understanding the nature of education by focusing on the externals...[hence we need to] begin a lengthy, systematic search of our inner experience' (p. 4). This paper thus heeds their call; however, as the following excerpt taken from John Holt's (1995) How Children Fail proposes, such 'systematic search' is by no means simple:

Watching older kids study, or try to study, I saw after a while that they were not sufficiently self-aware to know when their minds had wandered off the subject. When, by speaking his name, I called a daydreamer back to earth, he was always startled, not because he had thought I wouldn't notice that he had stopped studying, but because he hadn't noticed... Most of us have very imperfect control over our attention. Our minds slip away from duty before we realize that they are gone. Part of being a good student is learning to be aware of the state of one's own mind and the degree of one's own understanding. (pp. 7-8)

This observation positions us well within the methodological problems with which this paper is required to struggle. Even if we indeed wish to explore this hidden curriculum, it is not at all clear how we can do so. There are two levels of opaqueness we are to handle: (a) being outsiders to a student's daydreaming/mind-wandering or any other internal state of mind, we cannot tell what content s/he is experiencing. (b) as Holt argued, even the daydreamer seems to be somewhat incompetent in understanding his or her states of mind. The question then is, what kind of method can we apply toward the elucidation of this hidden curriculum? To address this the following is a brief demarcation of this hidden curriculum. Next, we will turn 
to the aid of cognitive science that has found some ingenious ways by which to address the matter.

\section{Demarcating the inner curriculum}

The following is a coarse fourfold categorization of what we can expect of a student's engagement with the enacted/taught curriculum:

A) Overt engaged learning - all manifestations of clear engagement with the subject matter taught; e.g., answering teacher's questions, raising the hand and waiting to be called, listening attentively to a fellow student or to the teacher's explanation.

B) Covert engaged learning - engaging with the subject matter by thinking about it or perhaps experiencing emotions/sensations that are directly evoked by the subject matter and the setting; e.g., stress before answering a question, satisfaction when one's answer is correct, a thought about a fellow student's response to the teacher's question.

C) Overt unrelated activities - social interactions that have nothing to do with the subject matter; e.g., talking to a fellow student about tonight's party, sending a note to someone else, texting under the table.

D) Covert unrelated activities - students who attend internally to their mental lives, experiencing content, which has nothing to do with the subject matter taught; e.g., butterflies in the stomach as a result of expecting a date with a girl in the evening, lingering memories from a frenzied morning, social-image thoughts.

Categories A, B \& C are the focus of the majority of educational theory, practice and research: A and B are generally what teachers and lecturers hope their students are doing during their lessons. $\mathrm{C}$ might be viewed as disruptive behavior that falls within the discourse of class-management. Category D is generally overlooked. Understandably, in contemporary discourse we would tend to frame it within the study of attentional deficits, or the improving 
of teaching practice, which are both worthy domains of study in their own right. Conversely, this paper seeks to mobilize category D from absence to presence in curriculum theory, research and perhaps, practice. Category D will here be referred to as the inner curriculum, which is defined as all inner experiences that a student (or teacher), young and adult, perceives within an educational setting that are not associated with the enacted curriculum in a direct way. The term 'educational setting' can be interpreted either as confined to educational institutions or as broad as life itself (Dewey, 1997a). The term 'inner experiences' refers to thoughts, sensations, emotions or any other mental states that a subject experiences, however, this paper will mostly focus on thoughts.

The elaboration of the inner curriculum requires further struggling with the methodological question of how to penetrate its opaqueness. For this purpose cognitive science can come to our aid as it has developed significantly in the past decades, based on research methods that rely on subjects' ability to report on their mental experience (Kahneman, 2011; Varela \& Shear, 1999). The ability to reflect on one's own thought processes has certainly received much attention in educational theory and practice in the discourse of reflection (Dewey, 1997a; Schön, 1987); however, this orientation has mostly relied on deliberate thinking processes, referred to as meta-cognition or higher-order thinking (Bishop et al. 2004). The study of the inner curriculum as it is elucidated in this paper, extends this orientation in two ways:

(a) Examining content that the subject has not deliberately invoked as in states such as daydreaming or mind-wandering, which Holt's citation seems to describe. Here, we can thus rely on studies in which subjects are randomly prompted (e.g., by an iphone application) with questions such as: what were you just doing? Were you thinking about what you were doing? If not, what were you thinking about? (Baars, 2010; Kahneman, 2011; Killingsworth \& 
Gilbert, 2010). Subjects are thus caught by surprise, and often as we shall see, they are found to be wandering.

(b) Examining practices in which students engage deliberately with the content of their own experience; specifically within the growing discourse of contemplative practices in education (Davidson et al, 2012). Most relevant to our case is mindfulness practice, which is growingly incorporated across curricular settings (Schonert-Reichl \& Roeser, 2016). Mindfulness is defined commonly as 'paying attention in the present, on purpose and nonjudgmentally' (Kabat-Zinn, 2005, p. 4) and has been depicted as antithetical to mindwandering (Mrazek, Smallwood, Schooler, 2012). In this case and as will be elaborated later, this orientation provides us with data on practitioners' states of mind, when these are intentionally accessed by them.

These two orientations enable access to unintentional and intentional dwellings in the inner curriculum. Both enable the combination of first-person subjective reports with subsequent analysis of these reports via qualitative and quantitative methods (Varela \& Shear, 1999). Building on a review of studies that have been conducted via these approaches, it is suggested here that we will be able to inform Pinar \& Grumet's (1976) call for a 'systematic search of our inner experience'. Findings gleaned from such method enable us to explore various features and effects of the inner curriculum, interpreted here as the mind's 'schooling itself' non-deliberately and/or deliberately.

The next section of the paper begins with a review of mind-wandering, task-unrelated, spontaneous and self-generated thinking. Then, the positive and negative effects of these states of mind are discussed from an educational perspective, and a structured way of understanding how the mind can be thought of as 'schooling itself' unwittingly is proposed. Finally, mindfulness practice is described as one way of the mind's 'schooling itself' deliberately. 


\section{Wandering and present minds in education}

[m] ore of our waking life than we should care to admit, even to ourselves, is likely to be whiled away in this inconsequential trifling with idle fancy and unsubstantial hope. (Dewey, 1997a, p. 2)

In recent years, empirical studies have been conducted in an attempt to assess how pervasive the mind's tendency to wander away from the present is, and what are the effects of this phenomenon. In an often-cited paper, Killingsworth and Gilbert (2010) studied 'mindwandering' habits of 2250 adults and its effects on their happiness. Subjects were randomly prompted 10 times a day by an iphone application reporting: what they were doing, what they were thinking about, and how they felt at that moment. Collecting over half a million samples Killingsworth and Gilbert found that mind-wandering - 'doing one thing yet thinking of another' (p. 932) - occurred close to half of these adults' waking hours. They also found that 'a wandering mind is an unhappy mind' as the title of their paper argues. Another study found slightly less wandering and 'non-task related' thinking; nevertheless, these states still occurred approximately in a third of the samples (Kane et al, 2007).

Whether we go with the higher or the lower assessment or whether we accept Dewey's claim above, it appears that we dedicate much of our time to thinking about what is not going around us. Adding Holt's perspective, it seems that we might not be aware of doing so. There is reason to believe that students who are asked to sit long hours in a classroom, study subject matter that they did not necessarily choose with a teacher they might not find interesting, at a time of day in which they might not be disposed to learning, are likely to spend at least some of the lesson absorbed in their own minds. The question is whether they 
are 'just missing' the planned curriculum, or whether the content produced by their own minds is 'schooling' them in 'alternative lessons'?

The past decade of research shows quite a unanimous agreement that mind-wandering is a significant phenomenon that affects our experience; however, there is ambivalence as to whether its effects are more positive or more negative. On the one hand, mind-wandering has been suggested to be a remarkable evolutionary achievement involving the maintenance of information for interpreting, responding to, and even predicting environmental demands, an achievement that allows people to learn, reason, plan (Schacter, Addis, \& Buckner, 2007; Raichle, 2015), and build mental models (Sood \& Jones, 2013). Some studies have thus been leaning toward presenting it as an adaptive, positive, and even desirable phenomenon (Baars, 2010; McMillan, Kaufman \& Singer, 2013; Smallwood \& Andrews-Hanna, 2013). On the other hand, much of the research shows that we pay an emotional cost for the tendency of our minds to wander. Mind-wandering has been associated with negative emotions (Smallwood, Fitzgerald, Miles \& Phillips, 2009; Smallwood, O’Connor, Sudbery, \& Obonsawin, 2007), rumination (Berman et al., 2011), unhappiness (Fell, 2012; Killingsworth \& Gilbert 2010). Importantly, some have found that mind-wandering affects socio-ethical disposition as it has been associated with reduced compassion (Jazaieri et al., 2016).

Some, however, have challenged the term 'mind-wandering' itself. The above review followed this term given its pervasiveness in the literature but various other terms have been applied to describe the broad domain discussed here including, day-dreaming, rumination, and task-irrelevant/self-generated/spontaneous thinking (Christoff et al., 2016; Mcmillan et al., 2013; Smallwood \& Schooler, 2014). Scholars have argued that these terms are not identical, hence there's a need for far more nuance in this domain (Baars, 2010; Christoff, 2012). For example, a crucial observation that Killingsworth \& Gilbert's paper fails to make, 
is whether the subjects they studied were indeed day-dreaming or whether they deliberately chose not to think of what they were doing. In the latter case, '(deliberate) reflection' might be a far more suitable term than 'wandering'. In our own above-mentioned categorization, a student's remembering her frenzied morning during a History lesson, may possibly manifest a mind's spontaneous adaptive strategy. That is, the mind processes unresolved events in order to clear the grounds for learning. These considerations suggest, that any of the terms applied to this inner curriculum may reflect assumptions and certain points of view that are not always warranted as some have indeed proposed (Baars, 2010; Christoff et al. 2016; Smallwood \& Andrews-Hannah, 2013).

Following the above and drawing us to educational discourse, at a primary coarse level, we can suggest that the reported effects of the inner curriculum on students' moods, emotions, creativity, mental model-construction, problem solving and other domains, can be associated with diverse educational discourses. Some examples include, education in wellbeing and happiness (Noddings, 2003), social-emotional learning (Durlak, Domitovich, Weissberg, \& Gullotta, 2015), thinking in education (Dewey, 1997a; Lipman, 2003), as well as education of character (Peters, 1967). Recalling Holt, becoming more mindful of our own states of mind may be crucial to the enhancement of learning, yet furthermore, this can also take us to the Delphic-Socratic 'know thyself' and to its more contemporary expressions in educational theory and practice (Pinar \& Grumet, 1976; Steel, 2014).

Having reviewed some of the effects of the inner curriculum and its associations with educational discourses we now turn to elucidate the mind as 'curriculum deliberator'. Based on more studies, we examine why would the mind choose to think of something other than the enacted curriculum, and why choose one type of content to think about over another? Exploring this domain will assist us in our attempt to assess what kind of agenda does the mind bring to the (classroom) table and how beneficial is it? 


\section{The mind's curricular deliberations}

The following, is a proposal of a way of examining the internal workings of a student's mind based on two interdependent yet methodically distinct components: process and content. Based on this distinction and informed by literature in the field, a structured way of approaching this internal domain is suggested, and later the idea of being 'schooled in our own minds' is developed.

Process: Our internal experience lends itself to a rough division between two kinds of processes, which concern our sense of agency - the sense that 'I am willing an action' and no less, that I am free to choose otherwise if I so wish (Alexander, 2005). Here, however, we will apply this to mental events (e.g., sensing, thinking). Setting aside what I think about, I can either choose to deliberately think about a certain issue $o r$ thoughts might come to mind unintentionally as my mind wanders spontaneously. In the first incidence, I feel myself to be willing the process of thinking, whereas in the second, I might be sitting in the classroom and find myself thinking about a certain issue, yet I can't recall what made me do so. Importantly, one can alternate between these states (Christoff et al., 2016); i.e., I might choose to think on one thing, wander, then come back to it, or a thought might come to mind spontaneously, catch my interest, and I then start to deliberately develop it.

Content: Willing the process of thinking is suggested here to imply an intention of practicing agency over the content of thinking. If during a Chemistry lesson, a student chooses to think about the upcoming summer and the need to get a job, this means that he chose to switch from attending to Chemistry, and he chose the content about which he thinks. However, during this very same Chemistry lesson that student can find himself thinking about the upcoming summer and the need to get a job, yet in such case, this happened without an 
aware sense of agency. The mind wandered there, but it could have wandered to a myriad other issues. In the latter case, the student is neither the agent of the process, nor the agent of the content, at least not in the same sense that he would have experienced had the course of things followed the first scenario.

Based on the above, the following is a coarse framework that depicts possible states of mind of the inner curriculum, some of which are explained hereafter:

\begin{tabular}{|c|l|}
\hline & Deliberate content Non-deliberate content \\
\hline Deliberate process & Contemplative practices (e.g. mindfulness, reflection) \\
\cline { 2 - 3 } & e.g., rumination, mind-wandering, day-dreaming \\
\hline \multirow{2}{*}{ Non-deliberate process } & \\
\hline
\end{tabular}

Table 1: Proposed framework for understanding states of mind within the inner curriculum

The framework proposed here is presents as a scaffold. Much further research will be required in order to make it more precise; however, it does allow some distinctions which rely on significant reviews of this field (Christoff et al. (2016); Smallwood \& Schooler (2014)) and enables insight into the inner curriculum. First, it responds to the need to explore the dynamics of mental events that develop over time, hence between deliberate and nondeliberate (process and content) a double-sided arrow is suggested to indicate fluidity between these categories. Furthermore, this framework acknowledges Christoff et al's distinction between mental states that are constrained in content versus those that are non- 
constrained. The former can be exemplified in rumination (often associated with depressive thinking) in which one's thoughts revolve around a limited subject (e.g., 'I always procrastinate, I'm such a procrastinator, why am I such a procrastinator?'). The latter is found in mind-wandering and daydreaming, which are non-constrained (i.e., they can begin with the thought about a summer-job, continue with 'what am I going to have for lunch?' and end in, 'why didn't she call me yesterday?').

Contemplative practices, are positioned as deliberate processes, following contemporary renditions. Davidson et al. (2012) defined them as 'activities that train skills by placing some constraint or imposing some discipline on a normally unregulated mental or physical habit. A defining characteristic of such practices is that they require individuals to exercise volitional control to sustain the focus of attention' (p. 147). They appear in the framework as running between deliberate content and non-deliberate content, depending on the kind of practice involved. Some practices, like focused attention, constrain the content to a specific object (e.g., the breath), others, like open monitoring, allow attention to wander freely, yet ask one to remain vigilant of the constantly changing content experienced (Slagter, Davidson \& Lutz, 2011). There are several examples of contemporary applications of contemplative practices in education (Barbezat \& Bush, 2014; Hansen, 2017; Lin, Oxford \& Brantmeier, 2013). Later on, mindfulness as perhaps the most commonly applied contemplative practice in education (Schonert-Reichl \& Roeser, 2016), will be elaborated as a deliberate schooling in one's own mind.

The main distinction between deliberate and non-deliberate processes has to do with the degree of one's awareness to the process. While some like McMillan et al. (2013) proposed mind-wandering as possibly a deliberate process of which one is aware, following Smallwood, McSpadden and Schooler (2007), here it is suggested that when one is 
wandering, one is unaware of the process of wandering, nor does he or she choose to engage in it. Rather, only when one finds herself wandering, awareness is there to acknowledge having been wandering. Nevertheless, one might still be aware of the content, for upon 'awakening' from wandering one can sometimes say what one was thinking about.

Based on the above matrix, we now explore the mind as 'curriculum deliberator' during non-deliberate processes (focusing on mind-wandering and rumination), then we explore it during mindfulness practice as a deliberate process. The distinction between process and content will come to our aid here, in our attempt to develop the idea of being 'schooled in our own minds'.

\section{Non-deliberate processes as a curricular deliberation}

Our attempt to consider non-deliberate processes as 'curricular deliberations' within the inner curriculum is clearly paradoxical and requires explanation. First, we are basically asking these two question: (a) what would make a student's mind 'decide' to switch from the enacted/taught curriculum to the inner curriculum? and (b) what makes the mind choose certain content rather than other? Second, what we are suggesting is that our lacking a sense of agency over processes and/or content that comes to our minds spontaneously, does not rule out the possibility that there is perhaps a natural intelligence or evolutionary 'reasoning' behind these non-deliberate processes and content, of which we are unaware. Such indeed has been the position of some scholars in this field (Baars, 2010; McMillan et al., 2013; Raichle, 2015). Referring to mind-wandering, Smallwood and Andrews-Hanna's (2013) expressed this idea as follows: 'any behavior that occupies such a large amount of time is a strong candidate for consideration as normal, if not important' (p. 1). Taking this position enables us to 
consider the mind's 'deciding' to wander to one thought or another in the midst of a lesson, as an adaptive process that may be beneficial. This approach will enable us to present some theories that have been proposed in cognitive and neuroscience in educational terms, and later, to suggest some critical responses to these theories. The following are thus some ways of considering non-deliberate processes and/or content as the mind's 'schooling itself' via its own 'curricular deliberations':

1. The 'proactive brain' - Assessing that an activity is non-significant, the mind may work to ready itself for the future by engaging in prospective mind-wandering (Baird, Smallwood, \& Schooler, 2011; Bar, 2009). This can entail various matters of personal relevance as well what has been termed 'theory of mind' (Saxe, Moran, Scholz, \& Gabrieli, 2006; Spreng, Mar, \& Kim, 2009); i.e., thoughts about what others are thinking, and what their intentions and beliefs are. The mind thus wanders to imagined or past scenarios as it orchestrates situations from our own and others' perspectives (Buckner \& Carroll, 2007). This suggests, that at least some of our mind-wandering content might revolve around the question 'what might happen next in my life?' whether this is related to the social arena or the physical environment. The process is thus designed to mentally rehearse possible scenarios that are to prepare us for future problems that might occur or correct past mistakes so as not to repeat them in the future. If we consider the curriculum in general as guided by the wish to prepare students for their adult life and engendering learning from past mistakes, this would certainly count as an adaptive and helpful process.

2. Consolidation of experience and dream-associated functionality - Studies have shown a clear affinity between dream mentation and mind-wandering, suggesting that the latter can be a moderate version of the former (Fox, Nijeboer, Solomonova, Domhoff, \& Christoff, 2013). Dreaming has been suggested as conducive to a learning process that consists of the 
consolidation of experience (Paller \& Voss, 2004). This can thus be applied to wandering in some cases. The mind that wanders may be 'catching up' on stimuli noted yet not fully cognized and processed at the moment of perception. It may thus be 're-teaching' itself the subject's experiences in order to further make meaning of them and internalize these lessons.

\section{A 'baseline' of arousal - Klinger (1971) suggested that maintaining a certain level of} arousal creates a baseline from which the brain can easily return to a task. We might think of this as how a computer functions efficiently. Rather than shutting down completely, which might require an energy and time-consuming rebooting, it simply shifts to 'screen saving' mode. This proposes another angle on the mind's curriculum deliberation. Here, content can be viewed as serving the process, rather than the other way around. The mind might be saving its resources so that when things get more important again, it will leap back to full attention.

4. The continuity of 'self' - the sense of 'mental time traveling' (Tulving, 1985) (i.e., thinking of past memories or imagining the future) has been strongly associated with narrative selfrelated processing (Northoff et al., 2006; Northoff \& Bermpohl, 2004; Qin \& Northoff, 2011). We recall past incidences and plan ahead, in order to maintain an autobiographical sense that constantly retags these thoughts and events as associated with 'me'. Perhaps mindwandering is a curricular deliberation that creates a stronger sense of continuous identity. This may be required for the mere sense of our sanity, well-being and even our ethical responsibility for our behaviors in the past and in the future.

5. Creativity - Perhaps phasing out of a task when it is simply not challenging enough or, in fact, when one is too absorbed in it, is an opportunity for the mind to engage in liberating itself from rigid thought patterns (Baird et al., 2012). Some (including scientists) suggest that it is within such loose thinking that they achieve their most significant breakthroughs rather 
than in those times in which they are fully focused on a problem (Dijksterhuis \& Meurs, 2006). Schools are often critiqued for reducing creativity. Perhaps students' wandering minds ameliorate this effect by phasing out of the rigidity of the conventions of our curricularpedagogical practice.

The above proposals shed positive light on the phenomenon of mind-wandering and follow Smallwood \& Andrews-Hanna's (2013) 'content regulation hypothesis'; i.e., the onset of the process reflects a natural 'economic' appraisal system that seeks to 'maximize the productivity of experience' (p. 4). Viewing things this way suggests that students' minds sometimes have better things to do than heed the enacted/taught curriculum. Whether this is about preparing for the future, 'catching up' on experience, maintaining our sense of identity, allowing room for creativity, or 'resting' - these all seem to be positive despite the social perspective that would deem them as 'missing out' on the planned curriculum. If we indeed follow this analysis alone, practically speaking, this would suggest either leaving things as they are by simply accepting the mind's tendency to wander, or in fact - bizarre as it might seem (and setting aside the question of how to do this) - encouraging wandering minds in schools.

However, if we speculate on this further from an evolutionary perspective and consider some significant research findings in this domain, we may have to reconsider such position for several reasons. If the mind indeed prepares itself for future survival, it would be inclined to rehearse possible threats more than pleasurable events, as Sood \& Jones (2013) suggested. Such orientation may yield more ruminative patters concerned with worrying about things that are not happening right now. Furthermore, remembering our past to create an autobiographical sense of 'self', sometimes leads to self-rebuke and self-pity as research on depression shows (Segal, Teasdale, \& Williams, 2002). No less, the creation of a cohesive 
'self' might at times work against us, if we for example, dwell on having been insulted in the past, and carry that insult with us into our future encounters with those that we see as responsible for how we feel.

The rather positive light that the naturalistic/evolutionary perspective sheds on our spontaneous thinking does not ameliorate some of its unsettling consequences. A student engaged in ruminative thinking about how 'she's never going to get math', or 'how she is going to flunk the next test' might not muster the motivation to change this script, and introduce change in her studentship. A student whose wandering-content is her teacher's disliking her, might not just miss subject matter; she may be entrenching a thinking habit that can clearly affect both how she feels during the lesson, and her attitude toward the subject matter itself. Wandering/ruminating during a lesson may revolve around a bullying experienced during recess, the shame and/or the plans of vengeance and not necessarily toward 'free associating' and enjoying the more creative aspects of mind-wandering.

When we look at the array of possibilities within this inner curriculum a more complex image arises. The question that might interest us then is, can we find a way to enjoy the positive effects of the inner curriculum and ameliorate the negative ones? In an attempt to consider this question, the following articulates a way of understanding the pedagogical mechanism that might be responsible for the more negative effects suggested above. This will further explain the idea of 'being schooled in our own minds' non-deliberately, and then lead us to consider pedagogies such as mindfulness practice as a deliberate 'schooling in our own minds'.

Non-deliberately schooled in our own mind 
Having been 'ejected' from a task such as a school-lesson into mind wandering/rumination, why would our mind take its content seriously when oftentimes, at least as far as we can tell, the content experienced does not seem helpful in any way? Why should we be affected by thoughts that are non-deliberate and often take us to scenarios that in retrospect seem completely off the mark?

One way proposed here for explaining these self-generated thoughts as having an effect on us, is that we believe them to be real even when we do not sense ourselves to have deliberately thought them. As Gilbert \& Wilson (2007) argued, mental simulation to the future and the past can be actually 'experienced' in the 'here and now', both at the level of sensations and at the level of their emotional consequences. Similarly, '[w]hen recalling an event from our past we do not simply bring to mind the incident in question. Rather, we mentally re-experience the event' (Phelps \& Sharot, 2008, p. 147). In fact, if these selfgenerated thoughts play an evolutionary role concerned with our future survival, then only if the mind will take them seriously will they actually serve their aim. That means that the effects of the mind's schooling itself during wandering/rumination must be based on an identification of the mind with its thought-content, such that will ensure the tagging of such fictitious events as educationally meaningful so that they will affect our future functioning. This invites a further exploration of the mechanism at work here.

In their study of mind-wandering Smallwood, McSpadden and Schooler (2007) titled their paper: The lights are on but no-one's home. They argued that mind-wandering involves a temporary failure in meta-awareness; i.e., the wanderer lacks the 'ability to reflect upon the content of [his or her] own mental state' (p. 527). However, this 'no-one' as it appears, can report in retrospect about what s/he was thinking about (as in Killingstworth \& Gilbert, 2010). The suggestion here, is that the idea of indoctrination in education, can help explain 
how mind-wandering as a lack of meta-awareness, schools us. Indoctrination can take various forms but it is usually defined based on one or more of the following four criteria: (a) Method; e.g., a teacher's disregard or intentional repression of students' critical faculties (Peters, 2010, p. 13), (b) Content; e.g., presenting false facts as true (Tan, 2008), (c) Intention; e.g., discouraging attempts to question the knowledge presented, or insisting on the truth of facts that are unwarranted in spite of critique (White, 2010, p. 125). (d) Results; e.g., the student ends up committing to beliefs that are impervious to proof (Tan, 2008, p. 2).

If we adopt the view that mind-wandering (and probably rumination as well, following Christoff et al (2016)) is a state in which we lack meta-awareness, then this implies a loss of authority over our minds. Such process thus becomes somewhat similar to an 'internal indoctrination'. This applies in a number of levels: (a) A student is not the agent of the on-set of the process - her mind seems to switch to mind-wandering without her being aware of it. (b) A student is not the agent of the content that the process will evoke. (c) When the content is there, she is not equipped with the ability to reflect on it and thus determine whether the content is worthwhile. All these suggest a version of the inner curriculum that is indoctrinatory. It is enacted by the mind and toward the mind. The following, points to two significant educational issues that come up here:

a) Agency: Wandering, and especially rumination, can feel somewhat like a movie that one cannot escape, despite the fact that one's own mind is responsible for its production. People suffering from this kind of content may feel that they are compelled to think these thoughts (Segal, Williams \& Teasdale, 2002). At the face of it, wandering can lead toward positive content such as 'I'm ready for this exam', 'that was quite an interesting lesson' in which case we may find this to be helpful. Yet, the fact of the matter is that we do not seem to be the agents that can determine what we will wander about since this state seems to be 
beyond our deliberate control. In addition, as Killingsworth and Gilbert (2010) found, the content of wandering is often negative and at least in as far as education is associated with happiness (Noddings, 2003), in their study positive wandering did not lead to changes in this respect, while negative content was found to reduce happiness.

The above then shows that we lack agency over the content of wandering, but we often lack agency over the onset of the process as well. We wander in spite of our wish to remain focused on driving during a traffic jam, or in classroom, in spite of our wish to do good academically. These cases bring the question of education in agency to center stage. As William James claimed:

The faculty of voluntarily bringing back a wandering attention, over and over again, is the very root of judgment, character, and will...An education which should improve this faculty would be the education par excellence. (2007, p. 401).

For James the whole drama of life depended on one's ability to sustain attention over desirable content and hence ban competing thoughts from the mind. If we are not in full control of our minds' switching from a school lesson to wandering, if we are not in control of the content we think about, and if wandering is as pervasive as studies suggest, how much agency can we actually attribute to students (and teachers)? While teachers are busy teaching diverse disciplines, there may be a pressing need to examine pedagogies that address this far more fundamental level of being present as we will soon examine.

b) Identity: As Dewey proposed, just as much as we have eating habits, we have thinking habits (1997b, p. 57). This points to the recursive nature of our minds. That is, our inner curriculum may follow patterns of thinking based on habit, even during processes like wandering and most clearly within rumination (Siegel, 2012, p. 195). Indeed Kabat-Zinn 
(2005, pp. 70-71) depicts mind-wandering as an unwitting 'practice', which is opposed to mindfulness soon to be described. Repeated patterns of thinking, whether witting or unwitting both express habitual patterns and entrench them. Education, however, is about changing students' minds in various ways. It is suspected that at least some of our mind-wandering content works to entrench our identities and may create resistance to change or resistance to education. Recalling the above, the consolidation of experience through the non-deliberate inner curriculum, may apply to the consolidation of our sense of identity (Northoff et al., 2006; Qin \& Northoff, 2011; Saxe et al., 2006). In this sense, from an educational perspective, we would hope that the identity that is consolidated would be more in tune with features of an 'educated person' (according to some conception of the term); however, 'no-one' is quite there to intervene in the process when it possibly goes astray.

Students arrive at a lesson with deep-seated dispositions that may have a substantial effect on their motivation to engage in learning (e.g., 'I'm never going to do well in math/history/literature', 'History is boring') and on their social image (e.g., 'everyone thinks I'm fat/stupid/ugly'). These may well be part of their non-deliberate inner curriculum. It may be true that long hours in school can be boring, but could it be that this also has to do with students' minds that have entrenched themselves in this disposition as they wander often to the thought 'this is boring'? This is surely not to suggest that teachers are free from doing their job as best they can by interesting their students. It is, however, suggested that perhaps we need to teach students to become more aware of their inner curriculum as it shapes their identity as learners and as people, and as it colors the ways in which they perceive their dayto-day educational experience.

It need be stressed that the above-mentioned scripts apply equally to teachers (e.g., 'I'm never going to get this class to listen', 'I hate teaching this class', 'I can't stand this 
student'). After a long day of teaching having to manage noisy classrooms, with all the stress involved in school life, it is plausible to suggest that teachers' minds may very well wander toward such content that might entrench negative dispositions that affect both them and their students. In this sense, mind-wandering/rumination may yield a reverberating effect: A teacher whose mind has schooled itself in 'I can't stand this student' encountering a student's mind schooled in 'this teacher always picks on me' may well be disastrous.

While we would not wish to lose the potential merits of the non-deliberate sides of the inner curriculum mentioned above, we would at least want to ameliorate the negative effects of depressive and ruminative thinking. There's a clear question of whether we can be that specific within such a blurry domain. As is now developed, research on mindfulness practice may be a fruitful domain to explore in this context.

\section{Deliberately schooled in our own mind}

The introduction of mindfulness (and other contemplative practices) into educational settings is already well under way (Felver, Hoyos, Tezanos, \& Singh, 2015; Greenberg \& Harris, 2012; Davidson et al, 2012; Zenner, Herrnleben-Kurz, \& Walach, 2014). Various mindfulness-based interventions are currently being offered, serving a variety of aims including, stress-reduction, improved attention, executive functions enhancement, the amelioration of teacher burnout, and well-being (Schonert-Reichl \& Roeser, 2016). In the context of this paper, the aim of mindfulness practice is to anchor the mind in the present moment and to cultivate one's awareness to one's inner curriculum; i.e. to one's mind processes and content (Kabat-Zinn, 2005; Wallace, 1999; Yates \& Immergut, 2015). 
During mindfulness practice, the anchor to the present moment is usually our sensed body. The practitioner will bring her attention to the breath or to bodily sensations. Whenever she notices her mind wandering away from it, she will reorient her attention back to these sensations (Kabat-Zinn, 2005; Yates \& Immergut, 2015). The moments within the practice in which one is focused on bodily sensations, or when one notes that s/he has wandered away from them are moments in which one is said to be in a state of mindfulness, here and now. The analysis of mindfulness, as a deliberate schooling in one's own mind, follows the same distinction between process and content proposed above:

First, mindfulness as concerned with process, means that a student engages in a formal practice the aim of which is to be present to her inner curriculum. Following Bishop et al's (2004) conception of the practice, mindfulness is antithetical to mind-wandering at the level of meta-awareness, for it implies actively noting what one is attending to (see also Mrazek et al., 2012). Essentially this is what students do in the classroom when they note that they have 'spaced out' from the lesson, and they wish to re-attend. Here, however, this switching of attention (Slagter et al., 2011) becomes the core and the aim of the pedagogy.

Second, targeting the process at the level of meta-awareness establishes a very different disposition of the mind toward the content experienced. This is the very shift from indoctrination to a non-indoctrinatory inner curriculum, for here, the mind shifts from an uncritical stance toward the content it presents to itself, to a mind that does not take its own content at face value. Most commonly, this disposition within mindfulness practice is referred to as non-judgementalism, curiosity and kindness toward that which is experienced (KabatZinn, 2005; Shapiro \& Carlson, 2009). Here one practices the willingness to observe the process of thinking (and/or emoting/sensing) itself, rather than becoming absorbed in the content and adopting it as a source for identification (Garland et al, 2015). 
What could be the educational merits of such practice? - responding to the two points raised earlier:

a) Concerning agency, the switching of attention from mind-wandering/rumination to mindfulness suggests a direct education in agency over the process, for one deliberately chooses to detach oneself from the lure of content produced by the mind during wandering or rumination. Consider that in our terms wandering means that the mind has made a curricular deliberation to opt out of an activity in which we were engaged (the enacted curriculum or any other), for the mind seemed to have appraised it as less significant. Choosing the less satisfying stimulus of the breath, over the content of wandering, reflects agency, as well as reduced identification with the content. By choosing it, one becomes an active curriculum deliberator who exercises agency over his or her own mind's temptation to wander. In so doing, one perhaps resists the indoctrinatory effects of content taught by the mind to an uncritical mind. Cognitive and neuroscientific research supports this proposition by demonstrating indeed that mindfulness practice cultivates the ability to sustain attention (Farb, Segal, \& Anderson, 2013; Hasenkamp \& Barsalou, 2012; Hölzel et al., 2011; Jha, Krompinger \& Baime, 2007; Tang, Hölzel, \& Posner, 2015). In addition, based on intensive meditation training, a trait reduction in mind-wandering has been demonstrated (MacLean et al., 2010; Mrazek et al., 2012).

b. Mind-wandering/rumination as possible change-resisting mechanisms - When a thought comes to mind, two possibilities emerge: (a) an automated habitual and nondeliberate track of wandering/rumination, which implies submitting oneself to this process and content, or (b) becoming mindful of the process and becoming capable of detachment from the lure of content. Track (a) is the habitual automated way. It is what we naturally tend to do, hence it implies less chance of introducing substantial changes in who we are (if such 
changes are desired). Track (b) implies straying from automation and introducing reflectively-based habits that Dewey (1997b), for example, considered to be the educational path that leads to 'growth'. The practice of mindfulness proposes a situation in which one is willing to question the validity of one's own unwitting and non-deliberate inner curriculum. It is this disposition of straying from automatism that may be one of the most significant characteristics of the educated person (Dewey, 1997a; Peters, 1967) for it expresses a willingness and freedom to become other than who I was yesterday, and strive for betterment now and in the future.

\section{Conclusion}

Curriculum discourse has rightly addressed the explicit, formal, taught, enacted and tested aspects of the curriculum; however, scholars have repeatedly pointed to the need to elucidate absence in our practice. This paper attempted to shed light on the inner curriculum as both a null curriculum that is hardly discussed, and a hidden curriculum as it seems to have a significant educational effect on us. During a school-lesson, students may be present in their bodies while heeding content created in their own minds. When this inner schooling occurs in a non-deliberate way via mind-wandering/rumination, the nature of this educational process may resemble an indoctrinatory educational process in which we are hardly the agents we believe we are. However, some studies depict these non-deliberate processes and the content they yield as adaptive. They contribute to our lives in diverse ways that can be associated with education. From the perspective of education in agency, we are more inclined to favor the cultivation of more awareness to our own minds' workings. If our thoughts are associated with our actions and behavior it would make sense that the curriculum would include practices that enhance our awareness to that which goes on in our own minds, how it affects us, and how will behave with others as a consequence. Thus, alongside mind-wandering as a 
non-deliberate schooling in our own mind, the paper examined mindfulness practice, that is becoming more noticeable in contemporary schooling, as one possible pedagogy through which we may cultivate more agency over our wandering minds. That said, however, while effects of the implementation of mindfulness in the curriculum seem promising (SchonertReichl \& Roeser, 2016; Zenner et al., 2014), many questions arise as to how to implement such uncanny practice within the curriculum. Furthermore, can there be adverse effects to this inward orientation? Are there prices that we might pay if indeed mind-wandering is reduced? This discourse is clearly in its infancy and many more studies are required in order to examine such issues as scholars in this field reiterate (Davidson et al., 2012; Greenberg \& Harris, 2012). The more we explore such practices, the more we will understand this inner curriculum that this paper sought to mobilize from absence to presence, in an attempt to broaden our understanding of curriculum theory and practice.

Word count: 9966 (including refs. not incl. acknowledgement, author bio, title page) 


\section{Acknowledgement}

I wish to acknowledge Dr. Aviva Berkovich-Ohana of the University of Haifa for her contribution to my understanding of the inner curriculum based on her expertise in neuroscience and cognitive science.

\section{Author Bio}

Oren Ergas $(\mathrm{PhD})$ lectures at the School of Education, Hebrew University, Israel and at the Faculty of education, Beit Berl College, Israel. Email: oren.ergas@mail.huji.ac.il. He studies the field of mind and body in the curriculum from philosophical and sociological perspectives. He is author of Reconstructing 'Education' through Mindful Attention (London: Palgrave Macmillan, 2017) and co-editor (with S. Todd) of Philosophy East/West: Exploring intersections between educational and contemplative practices (London: Wiley-Blackwell, 2016). 


\section{References}

Alexander, H. A. (2005). Education in ideology. Journal of Moral Education, 34(1), 1-18.

Baars, B. J. (2010). Spontaneous repetitive thoughts can be adaptive: Postscript on "mind wandering." Psychological Bulletin, 136(2), 208-210.

Baird, B., Smallwood, J., Mrazek, M. D., Kam, J. W. Y., Franklin, M. S., \& Schooler, J. W. (2012). Inspired by distraction: mind wandering facilitates creative incubation. Psychological Science, 23(10), 1117-1122.

Baird, B., Smallwood, J., \& Schooler, J. W. (2011). Back to the future: Autobiographical planning and the functionality of mind-wandering. Consciousness and Cognition, 20(4), 1604-1611. http://doi.org/10.1016/j.concog.2011.08.007

Bar, M. (2009). The proactive brain: memory for predictions. Philosophical Transactions of the Royal Society B: Biological Sciences, 364(1521), 1235-1243.

Barbezat, D., \& Bush, M. (2014). Contemplative practices in higher education : powerful methods to transform teaching and learning. San Francisco, California: Jossey-Bass.

Berman, M. G., Peltier, S., Nee, D. E., Kross, E., Deldin, P. J., \& Jonides, J. (2011). Depression, rumination and the default network. Social Cognitive and Affective Neuroscience, 6(5), 548-555.

Bhaskar, R. (2000) From East to West (London: Routledge).

Bishop, S. R., Lau, M., Shapiro, S., Carlson, L., Anderson, N. D., Carmody, J., ... Devins, G. (2004). Mindfulness: A proposed operational definition. Clinical Psychology: Science and Practice, 11(3), 230-241.

Brown, G. (2009) The ontological turn in education. Journal of Critical Realism, 8 (1), 5-34.

Buckner, R. L., \& Carroll, D. C. (2007). Self-projection and the brain. Trends in Cognitive Sciences, 11(2), 49-57. 
Christoff, K. (2012). Undirected thought: neural determinants and correlates. Brain Research, $1428,51-59$.

Christoff, K., Irving, Z. C., Fox, K. C., Spreng, R. N., \& Andrews-Hanna, J. R. (2016). Mindwandering as spontaneous thought: a dynamic framework. Nature Reviews Neuroscience.

Davidson, R., Dunne, J., Eccles, J. S., Engle, A., Greenberg, M., ... Vago, D. (2012). Contemplative practices and mental training: Prospects for American education. Child Development Perspectives, 6(2), 146-153.

Dewey, J. (1997a). How we think. Mineola, N.Y.: Dover Publications.

Dewey, J. (1997b). Democracy and education : an introduction to the philosophy of education. New York: Free Press.

Dijksterhuis, A., \& Meurs, T. (2006). Where creativity resides: The generative power of unconscious thought. Consciousness and Cognition, 15(1), 135-146.

Durlak, J. A., Domitovich, C. E., Weissberg, R. P., \& Gullotta, T. P. (n.d.). Handbook of social and emotional learning: Research and practice. New York: The Guilford Press.

Eisner, E. W. (1988). The primacy of experience and the politics of method. Educational Researcher, 17(5), 15-20.

Eisner, E. W. (1979). The educational imagination: on the design and evaluation of school programs. New York: Macmillan.

Farb, N. A. S., Segal, Z. V., \& Anderson, A. K. (2013). Mindfulness meditation training alters cortical representations of interoceptive attention. Social Cognitive and Affective Neuroscience, 8(1), 15-26.

Felver, J. C., Hoyos, C. E. C., Tezanos, K., \& Singh, N. N. (2015). A systematic review of mindfulness-based interventions for youth in school settings. Mindfulness, 1-12. 
Fox, K. C. R., Nijeboer, S., Solomonova, E., Domhoff, G. W., \& Christoff, K. (2013). Dreaming as mind wandering: evidence from functional neuroimaging and firstperson content reports. Frontiers in Human Neuroscience, 7, 412.

Garland, E. L., Farb, N. A., Goldin, P. R., \& Fredrickson, B. L. (2015). Mindfulness broadens awareness and builds eudaimonic meaning: A process model of mindful positive emotion regulation. Psychological Inquiry, 26(4), 293-314.

Gilbert, D. T., \& Wilson, T. D. (2007). Prospection: Experiencing the Future. Science, 317(5843), 1351-1354.

Greenberg, M. T., \& Harris, A. R. (2012). Nurturing mindfulness in children and youth: Current state of research. Child Development Perspectives, 6(2), 161-166.

Hansen D. T. (2017) Bearing witness to teaching and teachers, Journal of Curriculum Studies, 49 (1), 7-23.

Hasenkamp, W., \& Barsalou, L. W. (2012). Effects of meditation experience on functional connectivity of distributed brain networks. Frontiers in Human Neuroscience, 6, 114.

Holt, J. (1995). How children fail (Rev. ed.). Reading, Mass.: Perseua Books.

Hölzel, B. K., Lazar, S. W., Gard, T., Schuman-Olivier, Z., Vago, D. R., \& Ott, U. (2011). How does mindfulness meditation work? proposing mechanisms of action from a conceptual and neural perspective. Perspectives on Psychological Science, 6(6), 537559.

James, W. (1983). Talks to teachers on psychology and to students on some of life's ideals. Cambridge, Mass.: Harvard University Press.

James, W. (2007). The principles of psychology. New York, NY: Cosimo. 
Jazaieri, H., Lee, I. A., McGonigal, K., Jinpa, T., Doty, J. R., Gross, J. J., \& Goldin, P. R. (2016). A wandering mind is a less caring mind: Daily experience sampling during compassion meditation training. The Journal of Positive Psychology, 11(1), 37-50.

Jha, A. P., Krompinger, J., \& Baime, M. J. (2007). Mindfulness training modifies subsystems of attention. Cognitive, Affective, \& Behavioral Neuroscience, 7(2), 109-119.

Kabat-Zinn, J. (2005). Full catastrophe living : using the wisdom of your body and mind to face stress, pain, and illness (15th anniversary ed., Delta trade pbk. reissue). New York, N.Y.: Delta Trade Paperbacks.

Kahneman, D. (2011). Thinking, fast and slow. New York: Macmillan.

Kane, M. J., Brown, L. H., McVay, J. C., Silvia, P. J., Myin-Germeys, I., \& Kwapil, T. R. (2007). For whom the mind wanders, and when an experience-sampling study of working memory and executive control in daily life. Psychological Science, 18(7), $614-621$.

Killingsworth, M. A., \& Gilbert, D. T. (2010). A wandering mind is an unhappy mind. Science, 330(6006), 932-932.

Klinger, E. (1971). Structure and functions of fantasy. Wiley-Interscience.

Lipman, M. (2003). Thinking in education (2nd ed.). Cambridge ;New York: Cambridge University Press.

Lin, J., Oxford, R. L., \& Brantmeier, E. J. (Eds.). (2013). Re-envisioning higher education: Embodied pathways to wisdom and social transformation. Toronto: IAP.

McMillan, R. L., Kaufman, S. B., \& Singer, J. L. (2013). Ode to positive constructive daydreaming. Frontiers in Psychology, 4. http://doi.org/10.3389/fpsyg.2013.00626

Mrazek, M. D., Smallwood, J., \& Schooler, J. W. (2012). Mindfulness and mind-wandering: Finding convergence through opposing constructs. Emotion, 12, 442-448. 
Noddings, N. (2003). Happiness and education. Cambridge ;New York: Cambridge University Press.

Northoff, G., \& Bermpohl, F. (2004). Cortical midline structures and the self. Trends in Cognitive Sciences, 8(3), 102-107. http://doi.org/10.1016/j.tics.2004.01.004

Northoff, G., Heinzel, A., de Greck, M., Bermpohl, F., Dobrowolny, H., \& Panksepp, J. (2006). Self-referential processing in our brain - A meta-analysis of imaging studies on the self. NeuroImage, 31(1), 440-457.

Paller, K. A., \& Voss, J. L. (2004). Memory reactivation and consolidation during sleep. Learning \& Memory, 11(6), 664-670. http://doi.org/10.1101/lm.75704

Peters, R. (1967). The concept of education; London, Routledge \& K. Paul: Humanities P.

Phelps, E. A., \& Sharot, T. (2008). How (and why) emotion enhances the subjective sense of recollection. Current Directions in Psychological Science, 17(2), 147-152.

Pinar, W. F. \& Grumet, M. R., (1976). Toward a poor curriculum. University of Rochester, Kendall/Hunt publishing company

Postman, N. (1995). The end of education : redefining the value of school (1st ed.). New York: Knopf.

Qin, P., \& Northoff, G. (2011). How is our self related to midline regions and the defaultmode network? NeuroImage, 57(3), 1221-1233.

Raichle, M. E. (2015). The Brain's Default Mode Network. Annual Review of Neuroscience, $38(1), 433-447$.

Saxe, R., Moran, J. M., Scholz, J., \& Gabrieli, J. (2006). Overlapping and non-overlapping brain regions for theory of mind and self reflection in individual subjects. Social Cognitive and Affective Neuroscience, 1(3), 229-234.

Schacter, D. L., Addis, D. R., \& Buckner, R. L. (2007). Remembering the past to imagine the future: the prospective brain. Nature Reviews Neuroscience, 8(9), 657-661. 
Schön, D. A. (1987). Educating the reflective practitioner: Toward a new design for teaching and learning in the professions. San Francisco: Jossey-Bass.

Schonert-Reichl, K. \& Roeser, R. (2016). Handbook of mindfulness in education. New York: Springer

Schwab, J. J. (1969). The practical: A language for curriculum. The School Review, 78(1), 123.

Segal, Z., Teasdale, J. D., \& Williams, J. M. G. (2002). Mindfulness-based cognitive therapy for depression : a new approach to preventing relapse. New York: Guilford Press.

Shapiro, S. L., \& Carlson, L. E. (2009). The art and science of mindfulness: Integrating mindfulness into psychology and the helping professions (Vol. xvii). Washington, DC, US: American Psychological Association.

Siegel, D. (2012). The developing mind: how relationships and the brain interact to shape who we are (2nd ed.). New York: Guilford Press.

Slagter, H. A., Davidson, R. J., \& Lutz, A. (2011). Mental training as a tool in the neuroscientific study of brain and cognitive plasticity. Frontiers in Human Neuroscience, $5,17$.

Smallwood, J., \& Andrews-Hanna, J. (2013). Not all minds that wander are lost: the importance of a balanced perspective on the mind-wandering state. Frontiers in Psychology, 4. Retrieved from

Smallwood, J., Fitzgerald, A., Miles, L. K., \& Phillips, L. H. (2009). Shifting moods, wandering minds: negative moods lead the mind to wander. Emotion, 9(2), 271.

Smallwood, J., McSpadden, M., \& Schooler, J. W. (2007). The lights are on but no one's home: Meta-awareness and the decoupling of attention when the mind wanders. Psychonomic Bulletin \& Review, 14(3), 527-533. 
Smallwood, J., Fishman, D. J., \& Schooler, J. W. (2007). Counting the cost of an absent mind: Mind wandering as an underrecognized influence on educational performance. Psychonomic Bulletin \& Review, 14(2), 230-236.

Sood, A., \& Jones, D. T. (2013). On mind wandering, attention, brain networks, and meditation. Explore (New York, N.Y.), 9(3), 136-141.

Spreng, R. N., Mar, R. A., \& Kim, A. S. (2009). The common neural basis of autobiographical memory, prospection, navigation, theory of mind, and the default mode: a quantitative meta-analysis. Journal of Cognitive Neuroscience, 21(3), 489510.

Steel, S. (2014). The pursuit of wisdom and happiness in education: Historical sources and contemplative practices. SUNY Press.

Tan, C. (2008). Teaching without indoctrination: Implications for values education. Rotterdam/Taipei: Sense Publishers.

Tang, Y.-Y., Hölzel, B. K., \& Posner, M. I. (2015). The neuroscience of mindfulness meditation. Nature Reviews Neuroscience, 16(4), 213-225.

Tulving, E. (1985). Elements of episodic memory. Oxford Psychology Series, 2.

Varela, F. J., \& Shear, J. (1999). First-person methodologies: What, why, how. Journal of Consciousness studies, 6(2-3), 1-14.

Wallace, B. A. (1999). The Buddhist tradition of Samatha: Methods for refining and examining consciousness. Journal of Consciousness Studies, 6(2-3), 175-187.

White, J. P. (2010). Indoctrination. in R. S. Peters (ed.). The Concept of Education. London: Routledge. (pp. 123-133). 
Wilkinson M. L. N. (2014) The concept of the absent curriculum: the case of the Muslim contribution and the English National Curriculum for history, Journal of Curriculum Studies, 46:4, 419-440.

Yates, J. \& Immergut, M. (2015). The mind illuminated. Pearce: Dharma Treasure Press.

Zenner, C., Herrnleben-Kurz, S., \& Walach, H. (2014). Mindfulness-based interventions in schools - a systematic review and meta-analysis. Frontiers in Psychology, 5. 